\title{
Achieving sustainability, quality and access: lessons from the world's largest revolving drug fund in Khartoum
}

\author{
S. Witter ${ }^{1}$
}

ضمان الاستمرارية والجمودة والإتاحة: دروس من أكبر حندوق دوَّار للأدوية في العالم بالحرطوم صوفي ويتر

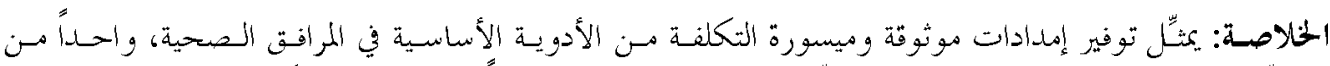

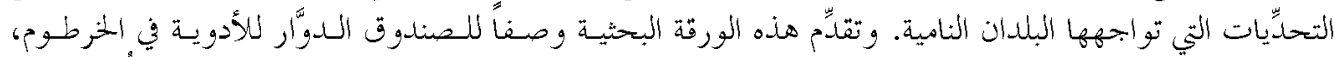

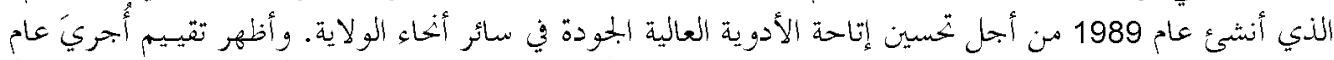

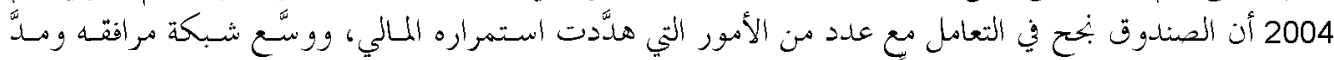

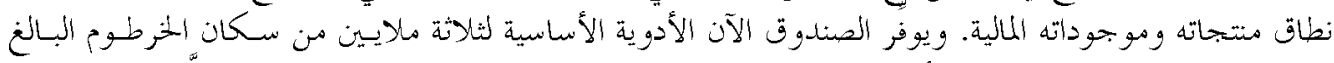

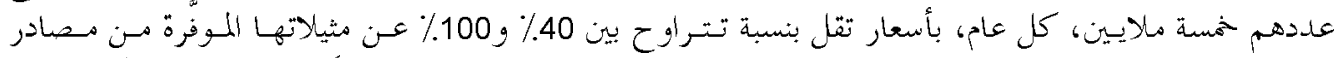

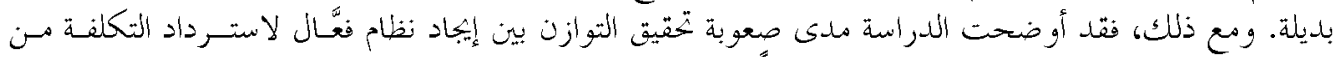

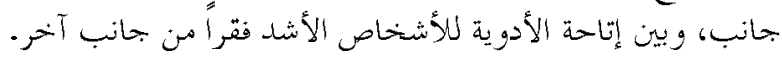

ABSTRACT Ensuring a reliable and affordable supply of essential drugs to health facilities is one of the main challenges facing developing countries. This paper describes the revolving drug fund in Khartoum, which was set up in 1989 to improve access to high quality drugs across the State. An evaluation in 2004 showed that the fund has successfully managed a number of threats to its financial sustainability and has expanded its network of facilities, its range of products and its financial assets. It now supplies essential drugs to 3 million out of the 5 million population of Khartoum each year, at prices between $40 \%$ and $100 \%$ less than alternative sources. However, results illustrated the tension between achieving an efficient cost-recovery system and access for the poorest.

Garantir viabilité, qualité et accès : l'expérience de Khartoum, le plus grand fonds renouvelable pour les médicaments au monde

RÉSUMÉ Garantir aux centres de santé un approvisionnement fiable et abordable en médicaments essentiels est l'un des principaux défis qu'ont à relever les pays en développement. Le présent article décrit le fonds renouvelable pour les médicaments de Khartoum, créé en 1989 afin d'améliorer l'accès à des médicaments de qualité sur tout le territoire national. Une évaluation réalisée en 2004 a montré que ce fonds a su surmonter avec succès les différentes menaces qui pesaient sur sa viabilité financière, tout en étendant son réseau de distribution, en élargissant sa gamme de produits et en multipliant ses investissements. Aujourd'hui, le fonds assure chaque année l'approvisionnement en médicaments essentiels de 3 millions d'habitants de Khartoum, qui compte une population de 5 millions, à des prix inférieurs de 40 à $100 \%$ à ceux pratiqués par d'autres distributeurs. Toutefois, les résultats mettent en lumière la difficulté qu'il y a à concilier un système de recouvrement des coûts efficace et l'accès des plus pauvres aux médicaments essentiels.

${ }^{1}$ Immpact, University of Aberdeen, Aberdeen, United Kingdom (Correspondence to: sophiewitter@ blueyonder.co.uk). 


\section{Background}

Drugs are a critical component of any health care system, and since the 1980s there have been a variety of experiments in developing countries with different approaches to cost recovery which aim to increase access to drugs. Some, such as the Bamako Initiative, use the willingness to pay for drugs to increase resources in the health sector generally $[1,2]$. Others operate strict cost recovery, using payments to purchase new drug supplies, but without any leakage of revenue for other purposes. One of the main features of many of these experiments is that they have been small-scale, and often not very long-lasting, due to a variety of managerial problems which lead to depletion of the original capital.

The importance of financing strategies for drug supplies is underlined by the fact that, generally speaking, developing countries spend a much higher proportion of their total health spending on drugs, $24 \%-66 \%$, compared with $7 \%-20 \%$ for developed countries [3]. In addition, the public spending on drugs as a proportion of total drug expenditure is typically much lower in developing countries $(5 \%-50 \%)$ compared with developed countries $(50 \%$ $90 \%$ ), leaving a heavy financial burden on households. Despite being costly, though, drugs are highly valued; studies in Sudan and elsewhere confirm that the availability of drugs is often seen as the key indicator of quality of health care by households [4].

The revolving drug fund (RDF) in Khartoum State, Sudan, is worth studying for 2 reasons: first, it is the largest single revolving drug fund in the world, with an annual turnover of $£ 2$ million and currently providing drugs to 3 million patients per year. Secondly, it has been in existence for nearly 2 decades now, and has been growing in scale and scope. The RDF now supplies
102 health centres, 18 hospitals and 18 community pharmacies. To run these it has 74 pharmacists, 202 pharmacy technicians and 297 support staff.

In 2004, an evaluation was commissioned to focus on how the RDF was functioning as an independent organization - whether it was still fulfilling its original mandate to supply quality drugs at below-market prices - and to examine which groups were benefiting from the RDF and how access could be extended to any groups found to be excluded. The team was also asked to draw out lessons for roll-out in other states of Sudan.

This paper presents the findings of the evaluation, in terms of financial sustainability, quality of drug supply and access, and the lessons for drug funds in other developing country contexts.

\section{History of the Khartoum RDF}

The RDF was jointly initiated by the Khartoum Ministry of Health $(\mathrm{MoH})$ and Save the Children (UK) in the mid-1980s, though it took until 1989 for the first drugs to be supplied to health centres. It arose in response to the weakness of the primary care system in the state and the increasing number of common childhood illnesses being brought to the Children's Emergency Hospital. The RDF was developed as part of a wider project - the Khartoum Comprehensive Child Care Project (KCCCP) - which aimed to revitalize primary health care services through improved drug supplies, equipment, staff training, refurbishment of health centres, and improving primary health care (PHC) systems.

The aims of the RDF component were to increase access to essential drugs at affordable prices and to encourage the rational use of drugs. The first was to be achieved

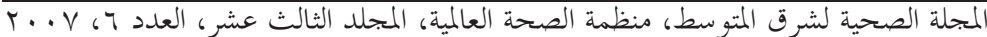


by setting up a sustainable drug revolving fund, with full cost recovery (but no subsidy to external activities, as was practised by the Bamako Initiative). The second was to be achieved by investment in infrastructure, training and operational research.

The RDF imports drugs from non-profit suppliers abroad, or from local sources, where these are available. A committee made up of RDF management and PHC representatives selects the drugs from the Sudan Essential Drugs List. These are then sold on at cost, plus a mark-up to cover overall running costs (including reserves against currency devaluation, etc.). Cross-subsidies are operated from the common, cheaper drugs to some of the more expensive ones. Prices for patients are uniform across the State: there is therefore some cross-subsidy from the closer facilities to the more remote ones, which are more expensive to supply and supervise.

Drugs are delivered to RDF-supported pharmacies in the health facilities, based on previous consumption patterns. Funds are collected monthly, against sales records. (For a more detailed description of the operation of the RDF, see [5]). An important point is that the RDF does not sell to the health centres to sell on (which would place the financial risk on the health centre), but sells directly to the patients, via pharmacies in health centres and hospitals.

Starting with 13 health centres in 1989 , the RDF expanded to 77 outlets (65 health centres and 12 rural hospitals) by 1996 . The list of essential drugs also expanded from 70 to 90 items. A total of US\$ 1.8 million was invested in capitalizing these outlets. Save the Children (UK) also provided training, refurbished pharmacies and provided transport until the programme was handed over in 1996 to the Khartoum $\mathrm{MoH}$ [6].

An evaluation of the overall KCCCP carried out in 1996 concluded that the RDF "was able to improve the supply system and avail a range of essential drugs at affordable prices" [7]. It also noted improvements in rational prescribing, though "efforts are still needed for further improvements in this area". It found that $8 \%$ of patients were unable to pay the prescription cost (this was based on the proportion of prescriptions where the drugs were available, but were not dispensed). It noted that the RDF policy of cost recovery had since become a key government policy in health throughout the country, and recommended that the RDF model be expanded nationwide.

During the next phase, 1996-2002, the RDF became an independent project within the Khartoum MoH. Changes over this period included the following:

- Financial incentives were introduced to retain staff.

- Training programmes were organized for all members of staff.

- A new employment contract was signed with pharmaceutical staff, whereby they would have to pay for stock losses. This reduced the leakage of drugs.

- Management improvements included a system for reconciling cash with the value of sales made, as well as $\mathrm{ABC}$ analysis of sales (investigating the proportion of revenue generated by different products).

- A policy of selling through the newly established "people's pharmacies" increased the number of outlets of the RDF, as did the expansion to a number of national hospitals.

- The RDF took responsibility for delivering free drugs for the first 24 hours of emergency treatment in public hospitals.

One study noted an increase in utilization of health facilities during this period that was attributed to the RDF and also to 
the new health insurance system introduced in 1997 [8].

In 2002, the Wali (Governor) of Khartoum State signed a constitutional decree on the establishment of the RDF as an independent foundation, responsible for the medical supply in Khartoum State. An independent administrative board was established, chaired by the State Minister for Health. At the same time, 7 RDFs were set up in other states, financed by the Central Medical Supplies Public Organization (CMSPO).

\section{Evaluation components}

The study was designed and approved by a steering committee, which included representatives of the Federal MoH, the Khartoum $\mathrm{MoH}$, the RDF, World Health Organization (WHO), United Nation's Children's Fund (UNICEF) and Save the Children (UK) [9]. Ethical approval for the research design, tools and sites was obtained from the Khartoum $\mathrm{MoH}$ and the Humanitarian Aid Commission.

There were 9 different components to this study:

- A literature review, to examine the RDF's history and also to fit the study findings into the context of wider developments in Sudan and internationally.

- Interviews with key informants in Khartoum, to assess the policy context and to identify concerns and suggestions for potential improvements to the RDF.

- A household economy approach study of different areas within the state, focussing on household livelihoods and coping strategies, and ability to afford health care and other basic goods [10].

- A household survey of 700 households (5111 individuals) looking at healthseeking behaviour, expenditure on health care, coping strategies and perceptions of health facilities and the RDF [11].

- Focus group discussions, which looked at the same questions as the household survey, but using qualitative techniques.

- A health facility survey, which looked at prescribing practices, financial management and pricing structures, and some indicators of quality of care within RDF outlets [12].

- A financial analysis of the RDF, to focus on profitability, operating costs, financial management and probity.

- A pharmaceutical study, to look at issues of quality, pricing, procurement, management and the range of drugs which the RDF supplies.

- A management study, focussing on the structure of the RDF, its human resource policies, management issues and legal status.

\section{Analysis}

\section{Financial sustainability}

Financial sustainability was measured in a number of ways, including by examining:

- the change in profit margins over time and from different revenue streams,

- the proportion of revenue expended on overheads (including staffing),

- various efficiency measures, such as working capital efficiency ratios.

- risks and liabilities to future sustainability.

The evaluation found that the RDF has continued to grow, in terms of its volume of sales and assets, and remains in good financial health. However, concerns were raised that increases in sales value, profit margins and salary costs could indicate that the primary ethos of the RDF was shifting

المجلة الصحية لشرق المتوسط، منظمة الصحة العالمية، المجلد الثالث عشر، العدد Y، V. Y. 
from a public health to a more commercial one.

In addition, some trends were noted towards less efficient management, such as increasing stocks (which increase the risk of losses), longer turnaround periods for stock, and the lack of some important information in financial reports.

One of the ways in which the RDF has expanded its business beyond the initial network of public health centres and hospitals (which are supplied with essential drugs) is by growing a semi-commercial wing, which supplies essential and non-essential drugs to the people's pharmacies. The high volumes and low overheads associated with this side of the business make it profitable, despite a lower mark-up. The removal of the people's pharmacies side of the business would pose a threat to the core business of the RDF.

There are a number of other threats to the long-term future of the RDF, which are common to funds of this kind. One is defaulting by debtors. The RDF supplies most of the public facilities in Khartoum State, including some tertiary referral centres. Unlike the health centres and hospitals (where the RDF sells direct to patients), the referral hospitals (which are federal institutions, not state) buy drugs themselves and some have not been paying promptly. They have considerable clout and it has taken delicate negotiations to reach a deal on payment of outstanding debts owed to the RDF. These issues, if unresolved, could threaten the RDF's credit rating with its creditors - the European not-for-profit suppliers which provide most of its imported drugs.

Financial independence has been crucial to the survival and success of the RDF. High level political support has helped to ensure that to date its funds have not been diverted to other uses. The RDF has traditionally paid a proportion of its profits to the Khartoum $\mathrm{MoH}$, originally to compensate for the
Ministry's investment in the health care and pharmacy infrastructure. The initial agreement between Save the Children (UK) and the $\mathrm{MoH}$ stated that $6 \%$ of the RDF sales should be transferred to the $\mathrm{MoH}$ to finance other PHC investments. The proportion of RDF sales revenue that is being transferred has increased, and the amount of money received by the $\mathrm{MoH}$ has doubled, in the light of the growth in RDF business and the addition of the income stream from the people's pharmacies (which did not exist when the original agreement was drawn up). It is also not entirely clear how the money is being used, and whether it is being invested in primary care or one of the tertiary institutions.

The RDF is also subject to a complex array of pharmaceutical regulations and tax concessions, which, if altered in a way that increased operating costs, could diminish its ability to continue to "revolve" successfully.

\section{Quality of drugs supply}

Quality of drugs supply was examined in 4 main ways:

- by looking at changes in prescriptions in relation to $\mathrm{WHO}$ rational prescribing indicators,

- by comparing drug prices at RDF outlets with market alternatives,

- by checking availability of essential drugs at RDF outlets,

- by investigating whether RDF supervision and quality control systems are still operating effectively.

The evaluation found that many of the systems - for procurement, quality assurance, distribution and stock control-continued to operate effectively. In addition, the market survey confirmed that the RDF continued to offer lower prices to its clients, compared with alternative outlets (it 
is $40 \%$ cheaper, on average across its list, compared to the CMSPO and $100 \%$ cheaper than private sector outlets).

However, there were some areas of concern. One was that the availability of essential drugs, while remaining good, had deteriorated since the last evaluation: the proportion of available stock in the facility had reduced from a reported $100 \%$ in health centres in 1996 and 2000 to $95.6 \%$ in 2004. Some indicators of rational drugs use had also deteriorated (in particular, there had been an increase in prescription of antibiotics). This suggests that renewed attention to prescriber training and public education is required. Systems for stock-keeping also appeared to be relatively poor in many of the RDF facilities - the number of health facilities stocking expired drugs had risen from $16 \%$ in 1996 to $28 \%$. These raised questions about the quality and robustness of the supervision which is being undertaken.

The RDF applies a cross-subsidy from cheaper to more expensive drugs, which increases access to costly items such as insulin. The equity effects of that are unclear, but it does mean that its prices, while lower on average for the full list than all its rivals, are higher compared with the CMSPO for the 15 most common drugs.

\section{Access}

Access was measured through 5 questions:

- How many people are being served by the RDF: what are the trends in utilization?

- Geographical access: are RDF services within reach?

- How many households, and what kinds of households, cannot afford to access RDF drugs and health services?

- How much awareness is there in the community of the RDF?
- What is the level of community participation in health services generally?

In terms of overall access, utilization trends were impressive (the RDF reached 3 million patients, some three-fifths of the total population of Khartoum State in 2002) but may have declined slightly in the last few years. Changes in reporting by the RDF and lack of a recent population census made it hard to track some of these issues.

Geographic coverage is good and there was no evidence that distance to facilities was a major barrier (it takes on average 15 minutes to reach a health centre and just over half an hour to reach a public hospital, according to the household survey). Quality indicators examined in the health facility survey suggested that quality did not vary systematically by location or rural/urban status, with the exception of supervision by the Khartoum $\mathrm{MoH}$, which was more frequent in urban areas.

The household survey also reinforced the importance of the public services: the main treatment strategy was to go to a health centre ( $36 \%$ overall), followed by public hospitals ( $29 \%$ overall). Moreover, these facilities are more important for the poor: use of health centres is concentrated in the bottom 3 quintiles, while hospitals are important to the bottom 4 quintiles, but not the richest.

Financial access is the main issue of concern, with the health sector charging for almost the entire range of health services and also, of course, the drugs. The household economy component of the study suggested that $17 \%$ of the population of Khartoum State were unable to afford basic health care costs, and $24 \%$ could meet basic costs but were unable to meet "emergency" costs, if they arose. These households are mainly composed of internally displaced people $(60 \%-75 \%$ of whom were estimated

المجلة الصحية لشرق المتوسط، منظمة الصحة العالمية، المجلد الثالث عشر، العدد T، Y... 
to be unable to meet their basic health care costs $)^{1}$, plus the poorest $5 \%-10 \%$ of the urban and rural households.

The household survey results are broadly consistent with the household economy approach results. It found that $51 \%$ of the overall sample were living in absolute poverty, but that the areas with internally displaced people were most affected $(66 \%$ of whom are under the poverty line), as well as being most disadvantaged in terms of infrastructure, which is also linked to higher rates of communicable disease. It found that $6 \%$ of the sick did not have treatment (largely for economic reasons), and that $29 \%$ of those who do treat cannot afford to pay for their treatment, resorting largely to borrowing or reduced treatment. For the internally displaced people areas, this was much higher (46\%), as it was when results were analysed by income quintile $37 \%$ of the bottom quintile could not afford to pay). Moreover, the poorest quintile was 5 times more likely not to treat sick members, compared with the top quintile.

These results related to overall health care costs, not just drug costs; however, drugs form the bulk of health care expenditure, according to the household survey, accounting for $58 \%$ of total costs. Overall, household expenditure on health care absorbs $1 \%-5 \%$ of total household income and averages US\$ 57 per person per year, much higher than previous estimates. Given that public spending on health averages US\$ 4 per person per year, these figures suggest that public sources are contributing a mere $7 \%$ of total health expenditure, at least within Khartoum State.

There are various formal mechanisms for protecting households against health care costs, but the survey suggests that they are only playing a small role. Only $1 \%$ of the sample had been exempted from paying for health care; $3 \%$ had had assistance from the Zakat Fund (an official charitable fund, based on mandatory payroll deductions), while a further 3\% had had assistance from Takaful (a voluntary fund set up to assist with hospital costs). In addition, just under $5 \%$ had benefited from insurance coverage (though this did not reduce the members' expenditure, rather it increased the proportion able to treat, especially at more expensive facilities). Informal channels appeared to be the most prolific and supportive- $57 \%$ of those who could not pay relied on borrowing to cover their bills - though these often create debts and future obligations.

Community awareness of the RDF was low: only $10 \%$ of household survey respondents had heard of it. Given that the $\mathrm{RDF}$ works through regular health service outlets, this low awareness is not surprising. In terms of community participation in those health services, the health facility survey found that $73 \%$ of the health centres and $50 \%$ of the hospitals reported having a functioning community health committee (CHC), but only $33 \%$ and $20 \%$ respectively had minutes of the meetings, which suggests that this may be a more realistic figure for active $\mathrm{CHCs}$. For the health centres with active committees, some $70 \%$ held monthly meetings, and the other $30 \%$ met weekly. These figures on availability of CHCs showed some improvement by comparison with the evaluation of 1996, though the proportion of health centres with an active committee remains less than a third.

\section{Lessons learned}

There are a number of general lessons that emerge from the RDF evaluation.

${ }^{1}$ The situation of the internally displaced people living in Khartoum has been affected by the peace agreement in the south and IDP data may now need to be reviewed. 
One is that there is an inherent tension in revolving drug funds between being business-minded (ensuring financial sustainability) and being philanthropic (ensuring access). The RDF originally managed the tension by coexisting with a project which focused on training and investments in the primary care network. Since 1996, when the project was handed over, and even more since 2002, when it became an independent organization, the temptation is there to focus on the business side, with less emphasis on looking for ways of increasing coverage for excluded groups. There is no trend data for exclusion, as it was not measured accurately in the past, but current data suggest that some $20 \%$ overall are either denied treatment or are having to resort to strategies which may threaten their future ability to cope. Although the RDF provides drugs at prices below those of competitors (thus improving relative affordability), it is unable to tackle issues of absolute affordability without endangering its own financial security.

The interaction with the health financing context is all-important. The RDF has been developed in the context of a health system which has increasingly been passing costs on to households. Since the 1990s, Sudan has been following the familiar path of health sector reform, including an increasing role for cost recovery (user fees), decentralization and encouraging the growth of the private sector [13]. This increases the willingness to pay for drugs (especially if they are accessible, of high quality and relatively cheap), while at the same time reducing the ability to pay, as households are already absorbing the full range of health care (and other) costs. In Khartoum, this tension has been manageable because of the buoyancy of the economy. In more remote parts of Sudan, evidence from what few reports exist suggests that revolving drug funds, where they were set up, have either ceased to function or have become the private businesses of individual health workers, seeking to supplement meagre salaries [14]. The importance of context has been emphasized by other studies which evaluated cost recovery programmes, for example McPake et al. [15].

In addition to the economic base in Khartoum, a number of other factors for the success of the RDF have been identified, which are of wider applicability. One is the large-scale and long-term investment which was made in establishing the RDF. The start-up took 7 years, with considerable technical and training inputs from Save the Children (UK), as well as a capital infusion of US\$ 1.8 million. Strong systems were established, and local technical competence and leadership built. The commitment of the political leadership of Khartoum to preserving the independence of the RDF, especially after handover, has also been crucial. In addition, the development of the national health insurance system has allowed the RDF to expand beyond what was previously affordable by the local population. A synergy has developed with the Khartoum Health Insurance Corporation, which is now its main purchaser. In 2003 it paid for 52\% of the sales through people's pharmacies and $43 \%$ of the sales through RDF outlets in health centres and hospitals.

Threats to financial sustainability need continued management, however. In particular, there is a temptation to change the purpose of a successful RDF, by extracting revenue for other purposes (making it more akin to a Bamako Initiative scheme, funding health care through drugs sales). If the funds are used to subsidise primary care and reduce user costs, then the effect could be cost-neutral on the users. However, in the case of the Khartoum RDF, this does not appear to have happened, in which

المجلة الصحية لشرق المتو سط، منظمة الصحة العالمية، المجلد الثالث عشر، العدد ب، V... 
case it is preferable to channel profits back into price reductions for drugs, or set the "excess profits" aside to fund exemptions for indigents. Other potential threats include political interference, poor leadership and weak management systems which allow overhead costs, losses and fraud to grow.

\section{Conclusion}

The RDF provides a useful model for other countries. It has survived for nearly 2 decades now and is continuing to fulfil its original mandate to supply high-quality essential drugs at below-market prices to a state of more than 5 million people. Most revolving drug funds fail due to problems such as under-capitalization, prices set below replacement costs, delays in cash flow, rapid programme expansion without sufficient additional capital, losses due to theft and deterioration, unanticipated price increases due to inflation and changes in parity rates or foreign exchange restrictions [16]. The $\mathrm{RDF}$, however, has gone from strength to strength, expanding its network, expanding coverage and range of products, and maintaining its price advantage over alternative sources.

The benefits are most marked in rural areas, which suffered from greater drug supply problems in the past (the private sector was less developed there) and which now benefit from the "one price" policy of the RDF (drugs cost the same throughout the RDF network, no matter how remote the facility). In ensuring a reliable and relatively affordable drug supply, the RDF has contributed to revitalizing the primary care system and has supported the growth since 1997 of a new national insurance scheme.

At the same time, the RDF is based on a strict cost-recovery mechanism, which has no built-in exemptions for those who are unable to pay. It is unable to square the circle of low incomes and high burden of illness, which lead to exclusion and financial hardship for around one fifth of the population. Drug funds, at their best, can improve availability and relative affordability, but in areas with high levels of absolute poverty, they cannot ensure access for all without external support. This is particularly true where cost recovery is applied not just to drugs, but to all health care services, as is the case in Sudan.

In Sudan, where the government provides one of the lowest proportions of total health expenditure in the whole of Africa (19\%, according to World Bank estimates), there is a strong case for increased public expenditure targeted at specific deprived regions and groups. This could be channelled through the health budget or through the growing health insurance system. In other countries which have developed revolving drug funds, other methods of reducing exclusion will need to be developed to complement their RDFs.

\section{Acknowledgements}

The author would like to acknowledge the inputs of the whole evaluation team, including Nichola Cadge, Lesley Adams, Muneef Babiker, K.E. Vaidyanathan, Ibtisam Ibrahim, Mohammed Awad al Karim, Nilesh Patwa, Yousif Abaker and Malony Tong, and of Save the Children (UK) for funding and managing this evaluation, with assistance from WHO and UNICEF. Thanks are also due to all key informants, including in the Ministry of Health and the RDF, and to those who commented on draft reports, including Regina Keith, Geraldine McCullough, and Gamal Kalafalla Mohammed. 


\section{References}

1. Kanji N. Charging for drugs in Africa: UNICEF's 'Bamako Initiative'. Health policy and planning, 1989, 4:110-20.

2. Soucat A et al. Local cost sharing in Bamako Initiative systems in Benin and Guinea: assuring the financial viability of primary health care. International journal of health planning and management, 1997, 12:S109-5.

3. Quick J. Drug financing strategies. Geneva, World Health Organization, Essential Drugs and Medicine Policy/ Health Technology and Pharmaceutical Cluster, 2000.

4. Habbani K, Groot W, Jelovac I. Household health-seeking behaviour in Khartoum, Sudan: the willingness to pay for public health services if these services are of good quality. Health policy, 2005 75(2): 140-58.

5. Ali GKM. Management of the revolving drug fund: experience of Khartoum State, Sudan [Masters thesis]. Bradford, United Kingdom, School of Pharmacy, University of Bradford, 2000 (http://dcc2.bumc. bu.edu/richardl/IH820/Resource_materials/RDF_Gamal.pdf, accessed 5 July 2007).

6. Tembon CA. Khartoum Comprehensive Child Care Programme: hand-over notes from SCF (UK) to $\mathrm{MoH}$ (Khartoum State). Khartoum, Khartoum Comprehensive Child Care Programme/Save the Children Fund (UK), 1996

7. AwadEIKarim PMA. Evaluation of the Khartoum Comprehensive Child Care Programme. Khartoum, Ministry of Health/ Save the Children Fund (UK), 1996.
8. Fundafunda B. Evaluation report on the Revolving Drug Fund at the Khartoum State Ministry of Health, 1998.

9. Witter $S$ et al. The Khartoum Revolving Drug Fund: an evaluation of sustainability, quality and access. London, Save the Children (UK), 2006.

10. Adams $\mathrm{L}$ et al. A household economy analysis of Khartoum State. Khartoum, Save the Children (UK), 2004.

11. Witter S, Babiker M. Costs and affordability of health care in Khartoum State: results of a household survey. Khartoum, Save the Children (UK), 2005.

12. Cadge N, Elkarim PM. Health facility survey of Revolving Drug Fund outlets for the evaluation of the Khartoum RDF. Khartoum, Save the Children (UK), 2005.

13. Babiker MA. The impact of liberalisation policy on health-some evidence from the Sudan. Sudan, Khartoum, University of Khartoum, Sudan 1996,

14. ElMuktar M, Saad Eldin M. Development of health service indicators for health areas. Khartoum, Federal Ministry of Health and World Health Organization, 2001,

15. McPake B, Hansen K, Mills A. Implementing the Bamako Initiative in Africa: a review and five case studies. London, London School of Hygiene and Tropical Medicine, 1992

16. Cross $P$ et al. Revolving drug funds: conducting business in the public sector. Social science and medicine, 1986, 22:335-43. 